\title{
El subsidio como arma represiva del Estado mexicano. La Universidad Michoacana de San Nicolás de Hidalgo durante la rectoría de Alberto Bremauntz (1963-1966) ${ }^{1}$
}

The subsidy as a repressive weapon of the mexican State. The Michoacán University of San Nicolás de Hidalgo during the rectory of Alberto Bremauntz (1963-1966)

O subsídio como arma repressiva do Estado mexicano. A Universidade Michoacana de San Nicolás de Hidalgo durante a retoria de Alberto Bremauntz (1963-1966)

\author{
Lucio Rangel Hernández ${ }^{2}$ \\ https://orcid.org/0000-0001-6453-0455 \\ Universidad Michoacana de San Nicolás de Hidalgo, México
}

Recepción: 20/09/2019

Evaluación:29/03/2020

Aceptación: 01/04/2020

Artículo de Investigación - Reflexión

https://doi.org/10.19053/01227238.10908

\section{RESUMEN}

Objetivo: El artículo se enfoca en establecer las razones que movieron al Estado mexicano a someter a la Universidad Michoacana a un ambiente de hostilidad y a un régimen represivo centrado esencialmente en el congelamiento del subsidio asignado para su funcionamiento; a mostrar cómo repercutió en la marcha de la casa de estudios esta política represiva; y a analizar la respuesta de la comunidad universitaria nicolaita ante esta embestida. A través de un método analítico y comparativo, contrastamos el subsidio otorgado a la universidad y en general la política educativa aplicada a la institución por el gobernador Agustín Arriaga Rivera, con respecto a la practicada por su antecesor, licenciado David Franco Rodríguez, para lo cual mediante la estrategia recurrimos a la consulta de fuentes documentales, bibliográficas, hemerográficas y orales. Este trabajo contribuye desde su originalidad al conocimiento de las conflictivas relaciones entre las

$1 \quad$ Este artículo forma parte de un proyecto de investigación más amplio titulado: "El Movimiento Estudiantil Nicolaita (1956-1966). La defensa de un modelo de universidad popular y nacionalista", que fue financiado por la Coordinación de la Investigación Científica de la Universidad Michoacana de San Nicolás de Hidalgo.

2 Doctor en Historia, profesor investigador de la UMSNH, Facultad de Historia/Colegio Primitivo y Nacional de San Nicolás de Hidalgo, correo electrónico: rhdezluc@hotmail.com 
universidades autónomas y el Estado autoritario mexicano. Como conclusión el resultado de esta investigación muestra que la permanente y sistemática política de hostigamiento se debió a la oposición de los nicolaitas ante la imposición del modelo educativo empresarial de origen estadounidense, en sustitución del modelo de universidad popular y nacionalista que habían heredado y adoptado desde los tiempos del régimen cardenista. Palabras clave: Subsidio; represión; Universidad Michoacana de San Nicolás de Hidalgo; modelo educativo popular y nacionalista; gestión universitaria.
The article focuses on establishing the reasons that moved the Mexican State personified in the figure of the Governor of Michoacán Agustín Arriaga Rivera to subdue the Michoacán University of San Nicolás de Hidalgo to an environment of hostility and a repressive regime that used various instruments and coercive resources but essentially focused on freezing the subsidy assigned for its operation; to show how this repressive policy affected the march of the institution; and to analyze the response of the Nicolaita university community to this onslaught.

With data obtained from the consultation of documentary, bibliographic, newspaper and oral sources, we contrast the budget support that the Governor Lic. David Franco Rodríguez (19561962) granted to the institution and the

\section{BSTRACT}

economic limitations and harassment and repression that he began to suffer with the arrival of Arriaga Rivera to the governorship of the entity (1962-1968).

The result of this investigation shows that the permanent and systematic policy of harassment that this ruler exercised over the university, was due to the opposition of the nicolaitans students to the imposition by the State of the corporate educational model of American origin. The fierce resistance that they presented is explained by the fact that they conceived their house of studies as heir to the Cardenista project of popular and nationalist orientation so they prepared to defend it.. Key words: subsidy, repression, Michoacan University of San Nicolás de Hidalgo, popular and nationalist educational model, university management.

\section{RESUMO}

$\mathrm{O}$ artigo se centra em estabelecer os motivos que levaram o Estado mexicano personificado na figura do governador de Michoacán Agustín Arriaga Rivera a sujeitar a Universidade Michoacán de San Nicolás de Hidalgo a um ambiente de hostilidade e a um regime repressivo que utilizou vários instrumentos e recursos coercitivos, mas essencialmente focado no congelamento do subsídio atribuído à sua operação; mostrar como essa política repressiva afetou a marcha da instituição; e analisar a resposta da comunidade universitária Nicolaita a esse ataque.

Com os dados obtidos a partir da consulta de fontes documentais, biblio-

gráficas, de jornais e orais, contrastamos o apoio orçamentário que o Governador Licenciado David Franco Rodríguez (1956-1962) concedeu à instituição e as limitações econômicas, assédio e repressão que ele começou a sofrer com a chegada de Arriaga Rivera ao governo da entidade (1962-1968).

O resultado desta pesquisa mostra que a política permanente e sistemática de assédio que esse governante exercia sobre a universidade se devia à oposição dos estudantes nicolaítas à imposição pelo Estado do modelo educacional empresarial de origem americana. A feroz resistência que eles apresentaram 
é explicada pelo fato de terem concebido sua casa de estudos como herdeira do projeto cardenista de orientação popular e nacionalista, dali que se prepararam para defendê-la.
Palavras-chave: subsídio, repressão, Universidade Michoacana de San Nicolás de Hidalgo, modelo educacional popular e nacionalista, gestão universitária.

\section{INTRODUCCIÓN}

El tema aquí tratado reviste particular importancia no solamente para la Universidad Michoacana sino para todas las Instituciones de Educación Superior de carácter público en México, puesto que desde su fundación en 1917 cuando se constituyó como universidad -si bien sus orígenes se encuentran en el siglo XVI bajo el nombre de Colegio de San Nicolás-y hasta la fecha, en lo fundamental requieren para su funcionamiento de la asignación de un subsidio proveniente del Estado, esto por más que han tratado de diversificar las fuentes de financiación y de incrementar sus ingresos propios. En ese sentido, el Estado ha utilizado el hecho de tener estipulado un presupuesto regular en ciertos momentos coyunturales como un instrumento de coerción y chantaje. Ahora mismo, por ejemplo, la universidad nicolaita, ha sido objeto no solamente del congelamiento sino de un recorte de su presupuesto por haberse negado a modificar su sistema de jubilaciones y pensiones ${ }^{3}$.

\section{Antecedentes}

Para el año de 1962, a raíz de la llegada al gobierno del Estado de Agustín Arriaga Rivera, las relaciones entre la Universidad Michoacana y el poder público comenzaron a friccionarse. De esta manera cuando la institución se encontraba en una etapa de pleno ascenso académico bajo la rectoría del Dr. Elí de Gortari, un grupo de profesores que se integraron en la autodenominada "fraternidad antidegortarista", provocaron un conflicto interno que vino a interrumpir el proyecto de una universidad moderna pero de corte popular y nacionalista. Este enfrentamiento como expresión de las diferencias suscitadas por el modelo de universidad a seguir, dio la oportunidad al ejecutivo estatal para tratar de imponerle a la máxima casa de estudios de Michoacán los principios modernizantes del Estado mexicano, provenientes del periodo presidencial de Ávila Camacho (1940-1946), expidiendo una nueva Ley Orgánica el 14 de marzo de 1963, abrogando la hasta entonces vigente desde 1961, misma que fue considerada en su momento como la más avanzada con que había contado la institución. Para protestar contra esta acción autoritaria, los universitarios nicolaitas salieron a las calles, donde recibieron la respuesta represiva violenta del Estado, que ocasionó la muerte de Manuel Oropeza García y heridas a seis estudiantes más.

3 Javier Fabela, “'Tijerazo’ en 40 dependencias”, La Voz de Michoacán, (2016): 16. 


\section{La llegada de Alberto Bremauntz a la rectoría}

Después de la represión gubernamental que a sangre y fuego ahogó la protesta estudiantil contra la derogación de la Ley Orgánica de 1961, se desató una feroz persecución y encarcelamiento contra los líderes, tanto estudiantiles como magisteriales. Los distinguidos maestros que habían llegado a la universidad, invitados por la administración de De Gortari, y que fueron aprehendidos por defender su causa, obtuvieron su libertad a condición de abandonar el Estado ${ }^{4}$.

De la misma manera, tanto como recurso para 'apaciguar' los aislados focos de resistencia que todavía quedaban, como para justificar la imputación de la malversación de los fondos universitarios hecha a De Gortari, el gobierno estatal suspendió "las remesas de dinero a la Universidad, dándose el caso nunca visto de que durara hasta dos meses sin pagar a maestros y empleados, ni las becas a los estudiantes" ${ }^{\prime}$.

Con el sector más combativo descabezado y desmovilizado por la fuerza de la represión, el gobernador quedó con la 'vía libre' para imponer a los miembros de la recién creada Junta de Gobierno y al propio rector.

La Junta de "Notables", quedó integrada así: Dr. Enrique Arreguín Vélez, Dr. Carlos García de León, Prof. Raúl Arreola Cortés, Lic. Antonio Martínez Baéz, Lic. Gabino Fraga y Lic. Pablo G. Macías,

personalidades, todas ellas, de honesta y limpia trayectoria, que en otras circunstancias hubieran llenado de satisfacción a todos, su arribo a los órganos de gobierno de nuestra Universidad, pero en esas condiciones no, incluso se les cuestionó, el haberse prestado a colaborar con un gobierno que se había manchado de sangre nicolaita, y ellos respondieron que lo hicieron para evitar que la institución cayera en manos reaccionarias, hecho que a la distancia de 31 años hay que reconocer que estuvo correcto 6 .

Inmediatamente después, la Junta, a propuesta del gobernador, designó como rector provisional al Lic. Alberto Bremauntz, profesionista de amplia trayectoria pero que tampoco fue bien recibido por el origen mismo de su nombramiento ${ }^{7}$. Al designar a estos distinguidos personajes, Arriaga Rivera pretendió que su régimen no fuese señalado abiertamente de retrógrado, pero una vez reestablecidas las actividades en la universidad y reestructurados sus órganos de gobierno, para poder controlarla buscó infiltrar a sus incondicionales en la dirección. Prueba de ello fue el incidente que se suscitó cuando el propio gobernador

$4 \quad$ El caso del maestro de historia y ciencias políticas Juan Brom fue extremo. Sin saber qué le esperaba, en medio de la noche lo trasladaron a varios kilómetros fuera de la ciudad de Morelia, y se lo entregaron al recién nombrado rector, Lic. Alberto Bremauntz, quien había intercedido por él. Adolfo Mejía González, Michoacán feudo cardenista? Historia de una lucha estudiantil vencida con la traición y el asesinato (México: Editorial Nuevos Caminos, 1966), 163.

5 Ibíd., 164-165.

6 Entrevista a Mejía González Adolfo, Morelia (Michoacán), 23 de agosto de 1994.

7 Mejía González, Michoacán, 164-165. 
le pidió al rector, separar del cargo de secretario general al Lic. Alfredo Gálvez Bravo y este no accedió, por lo que lo presionó incluso a través del secretario de Educación Pública, Lic. Jaime Torres Bodet, a lo cual continuó negándose; pero como Gálvez Bravo se enteró del asunto, consciente de las dificultades que su permanencia podía acarrear a la institución, con la desavenencia, tanto del gobierno estatal como federal, decidió renunciar". En su lugar, por "petición" del secretario general de Gobierno, nombró al Lic. Jesús Arreola Belmán, quien se dedicó, aparte de las funciones inherentes a su puesto, a reportar al gobierno del Estado las actividades de los universitarios, especialmente las del rector Bremauntz, por lo que al enterarse, lo separó del cargo, sustituyéndolo por el Lic. Eugenio Aguilar Cortés9.

Algo semejante ocurrió con el Lic. Jesús Bravo Baquero, regente del Colegio de San Nicolás, despedido por los mismos motivos ${ }^{10}$. El Lic. Bravo Baquero conformó entonces, la Sociedad de Profesores Universitarios "Melchor Ocampo", que editó varios folletos desde donde se atacaban por igual el trabajo y las ideas del rector, consignadas en sus libros, contando con la ayuda del gobierno estatal para su impresión ${ }^{11}$.

En estas condiciones, cuando la Junta de Gobierno promovió la auscultación para nombrar rector definitivo, el gobernador le "sugirió" la designación como tal, de Arreola Belmán, pero como la Federación de Estudiantes Universitarios de Michoacán (FEUM), conjuntamente con un grupo de profesores y personal administrativo, en escrito del 16 de mayo de 1963, manifestó su apoyo a Bremauntz, el mencionado órgano de gobierno, decidió nombrarlo rector definitivo, el 3 de agosto de 1963, contrariando la voluntad de Arriaga Rivera ${ }^{12}$.

\section{La recuperación de los organismos estudiantiles de manos del porrismo ${ }^{13}$}

Paralelamente, el gobierno del Estado, aprovechando la dispersión en que se encontraba el alumnado, intentó apoderarse de las direcciones de las organizaciones estudiantiles, primordialmente de la FEUM, por ser el organismo que las aglutinaba, con el objeto de tomar el control e impedir así, toda oposición a su política antiuniversitaria y antipopular.

Inicialmente logró dicho objetivo por medio de la corrupción y la cooptación de dirigentes como Jesús Plancarte, quien presidió la FEUM en 1964, y luego a través de un fraude electoral, imponiendo a Álvaro Miranda en 1965, quien se mostró como candidato independiente cuando en realidad era miembro de las

\footnotetext{
Alberto Bremauntz, Setenta años de mi vida. Memorias y anécdotas (México: Ediciones Jurídico Sociales, 1968 ), 168. Ibíd., 169.

Ibíd., 162.

Ibíd., 171.

Ibíd., 171.

13 Los porros eran grupos de jóvenes universitarios corrompidos y financiados por el gobierno del Estado y el partido oficial (PRI) para acudir a los eventos políticos de los estudiantes organizados y tratar de controlarlos por medio de la violencia o del amago de utilizarla. El porrismo en México se originó en la UNAM y en sus inicios, estos grupos utilizaban "cachiporras" para golpear a los estudiantes o grupos rivales, de donde se derivó el nombre.
} 
juventudes del Partido Revolucionario Institucional (PRI). Por esto, la mayor parte del estudiantado lo repudió y le criticó duramente el hecho de estar "ostentando una representación nacida de la triquiñuela y la artimaña"14.

A la conclusión del periodo de Miranda, al frente de la FEUM, hubo un nuevo intento de imposición, pretendiendo que el nombramiento de presidente, recayera en Jesús Avellaneda Borja. Recuerda el entonces presidente del Consejo Estudiantil Nicolaita (CEN), Cuauhtémoc Olmedo Ortiz, que en las elecciones, cuando simpatizantes del candidato gobiernista se dieron cuenta de que iban perdiendo, se apoderaron de las urnas y se autoproclamaron triunfadores. Pero ya para esos momentos, el estudiantado nicolaita que estaba en vías de recuperar sus organizaciones, exigió un referéndum, el cual fue aplicado por el CEN, resultando que, como el grupo priísta no se presentó al mismo, Raúl Galván Leonardo fue reconocido como su legítimo dirigente ${ }^{15}$.

A pesar de ello, Avellaneda Borja continuó pavoneándose como presidente de la FEUM, sin contar con el consenso de los estudiantes universitarios, creándose con ello, una organización paralela a la legalmente constituida. El objetivo era mantener dividido al estudiantado, lo que no les resultó, puesto que sin el apoyo de las bases, Avellaneda Borja terminó por opacarse, a pesar de que el gobierno del Estado y el Comité Directivo Estatal del PRI lo apoyaron para organizar ateneos, círculos literarios, asociaciones culturales y equipos deportivos. ${ }^{16}$

Con todo, la recuperación del movimiento estudiantil democrático, iba en pleno ascenso; en ello tuvo mucho que ver, sin duda, la celebración en mayo de 1963, de la Primera Conferencia Nacional de Estudiantes Democráticos, ya que con la participación y el fogueo de sus líderes en las reuniones previas a la fundación de la Central Nacional de Estudiantes Democráticos (CNED), y ya conformada ésta, el movimiento estudiantil local, recuperó terreno poco a poco hasta convertirse en uno de los pilares más fuertes en el país de la nueva central estudiantil.

Una vez conformada la CNED, su dirigencia desplegó una gran actividad nacional con el propósito de aglutinar a los organismos estudiantiles de tendencias democráticas, para organizarlos en defensa de la educación popular y nacionalista. Fueron convocadas con este objeto, varias reuniones del comité directivo en Morelia, ciudad que se convirtió, prácticamente en la sede de la central estudiantil. Por ello, aseveramos que este fue uno de los principales factores que permitieron la reorganización y reanimación del movimiento estudiantil michoacano, después de la represión de la que había sido objeto en marzo de 1963.

14 "Neofacismo en la Universidad", FEUM, Órgano de Difusión de la Federación de Estudiantes Universitarios de Michoacán, nº 1 , (1964): 1,7

15 Entrevista a Olmedo Ortiz, Cuauhtémoc, Morelia (Michoacán), $1^{\circ}$. de febrero de 1991.

16 "Situación política de la Universidad Michoacana de San Nicolás de Hidalgo", Informe del agente I.N.V. (19 de marzo de 1966), Archivo General de la Nación, fondo Dirección General de Investigaciones Políticas y Sociales (AGN/IPS), Caja 456. 


\section{El grupo de choque}

Frente a la reorganización del estudiantado y la consecuente reanimación del movimiento estudiantil nicolaita, el gobierno del Estado puso en práctica, variadas formas de intervención en la universidad para obstaculizar su reagrupación. El gobernador Arriaga Rivera, por medio del Lic. Mario Ruiz Aburto, presidente del CDE del PRI, incrustó en la universidad a un grupo de jóvenes pertenecientes a la sección juvenil de ese partido, para que sirvieran como grupo de choque, y así, confundidos entre los verdaderos estudiantes, realizaban misiones policíacas de espionaje, sabotaje y represión de las actividades estudiantiles universitarias ${ }^{17}$. Es importante mencionar que, como una derivación de lo que ocurría a nivel federal, bajo el régimen autoritario mexicano, la policía, tanto la Judicial del Estado como la 'secreta', se encontraban fuera del control del procurador. Las órdenes emanaban del sub procurador, del jefe de la Judicial, Héctor Ruiz Aburto y del dirigente estatal del PRI, Mario Ruiz Aburto, personaje este último, de toda la confianza del gobernador ${ }^{18}$.

El 7 de mayo de 1963, este grupo de choque, se introdujo con armas de fuego en el taller donde se imprimía El Nicolaita, órgano de difusión del CEN, y después de golpear a sus redactores, los despojó de todos los ejemplares ${ }^{19}$. En contrapartida, elaboraban y repartían panfletos de organizaciones estudiantiles "fantasmas" ${ }^{20}$, para tratar de confundir al estudiantado.

En varias ocasiones, durante los meses de mayo y junio de ese año, el mismo grupo baleó durante las noches las fachadas de las Casas del Estudiante. Además, por esas fechas, utilizando métodos gansteriles, esa banda de pseudoestudiantes, robó y destruyó el busto y el pedestal, aún sin terminar, del monumento que sería erigido en memoria de Manuel Oropeza García, el joven nicolaita, caído en la jornada de marzo, víctima de la represión gubernamental ${ }^{21}$.

Esa campaña de hostigamiento e intimidación perpetrada por el grupo de choque priísta, incrustado en la universidad, se orientó especialmente contra los elementos destacados del movimiento estudiantil democrático como Belizario Piña Martínez, estudiante de la Escuela de Derecho y profesor del bachillerato, a quien le propinaron brutal golpiza. De la misma forma, el 24 agosto de 1964, secuestraron en Morelia al estudiante de origen bajacaliforniano, Rafael Aguilar Talamantes, dirigente de la CNED, quien señala:

Me trasladaron hasta los límites de los estados de Michoacán y de México, me fueron golpeando durante todo el camino; ya en un paraje alejado de la carretera, me desnudaron y me hicieron cavar mi propia tumba y una vez terminada, me

17 "Neofacismo en la Universidad".

18 "Antecedentes del problema de la Universidad Michoacana de San Nicolás de Hidalgo", (4 de octubre de 1966), AGN/IPS, caja 455.

19 "Atraco priísta", El Nicolaita, época XI, no. 47 (1963): 1, 6; "Neofacismo en la Universidad".

20 "Antecedentes del problema de la Universidad Michoacana de San Nicolás de Hidalgo".

21 "Neofacismo en la Universidad". 
pusieron una pistola en la cabeza y un cuchillo en el cuello, y cuando ya esperaba que me mataran, un agente me gritó amenazante: "hijo de tu chingada madre, no te queremos volver a ver en Michoacán, porque ahora sí te mueres", y luego me abandonaron golpeado, sin ropa y sin zapatos ${ }^{22}$.

Ellos mismos, en abril de 1965, golpearon al Lic. Arnaldo Córdoba, docente de la Escuela de Derecho, a causa, seguramente de su manifiesta ideología socia$\operatorname{lista}^{23}$. Ante esta serie de atentados, que ya constituían una abierta provocación, los universitarios nicolaitas, no cayeron en la trampa de responder, porque comprendieron que el objetivo del gobierno estatal era llevar a la universidad a un clima de violencia y encerrarla en un "callejón sin salida", para luego justificar su intervención, hasta con el ejército, con el argumento de "recuperar la tranquilidad y el orden". En su lugar, por medio del Consejo Universitario, exigieron una investigación de los hechos, para dar con los culpables y detener la ola de agresiones que se había desatado, pero el gobierno no procedió, anteponiendo el conveniente y demagógico discurso de que era "respetuoso de la autonomía universitaria" ${ }^{24}$.

\section{El presupuesto 'congelado'}

Por todos los medios, el régimen arriaguista buscó doblegar a la universidad, para que cumpliera sus designios, y en esa medida, blandió la "espada de Damocles", congelándole el subsidio. El presupuesto no fue aumentado por el gobierno del Estado y tampoco por el federal, de acuerdo con los nuevos requerimientos, en virtud del crecimiento que había experimentado con la creación de escuelas, facultades e institutos y el consecuente incremento de la población estudiantil, durante el rectorado de De Gortari.

A la institución le urgía el aumento presupuestal para mejorar y ampliar los servicios asistenciales en las Casas del Estudiante, así como acrecentar el número y la percepción de las becas a los alumnos de escasos recursos económicos, para incrementar las plazas de profesores de carrera, para la contratación de más personal docente, administrativo y de intendencia, para la construcción de la infraestructura necesaria para albergar a las nuevas dependencias, para el montaje y equipamiento de laboratorios que varias de estas requerían, y la renovación de otros, para dar realidad a la fundación de los Institutos de Investigaciones Químicas e Históricas, y para poner en marcha nuevos programas de licenciatura ya proyectados como el de Letras Españolas, propuesto por

\footnotetext{
22 Entrevista a Aguilar Talamantes, Rafael Ignacio, ciudad de México, 27 de octubre de 2015; véase también "Declaración de la Juventud Comunista de México al Estudiantado y al pueblo de México" (Morelia, 25 de agosto de 1964), Archivo Particular de Hiram Ballesteros Olivares (APHB); "Protesta General Universitaria por la Desaparición de un Líder Nacional", La Voz de Michoacán, (1964): 12; “Apareció en el D.F. el líder A. Talamantes", Ibíd.

23 "Protestas contra la agresión a un catedrático", La Voz de Michoacán, (1965): 5.

24 "Intervención del gobierno en la Universidad", FEUM, Órgano de Difusión de la Federación de Estudiantes Universitarios de Michoacán, época I, $\mathrm{n}^{\circ} 1,(1964): 3,4$.
} 
el Consejo Técnico de la Facultad de Altos Estudios "Melchor Ocampo"25. Igualmente para ampliar la cobertura del bachillerato en la ciudad, ya que la demanda había crecido tanto que no cabían en el Colegio de San Nicolás, donde, de acuerdo con el maestro Ramón Martínez Ocaranza, las secciones se componían de más de setenta alumnos, lo que constituía un serio obstáculo pedagógico $^{26}$. Pero, el tan necesitado aumento al subsidio universitario, de acuerdo con dichos requerimientos, nunca llegó. Estaba claro que tanto el gobierno estatal como el federal, no estaban dispuestos a apoyar a una institución defensora del proyecto cardenista de educación popular y nacionalista, a la cual consideraban como una institución "rojilla". En el fondo, el 'congelamiento' del presupuesto, obedecía al hecho de que la Universidad Michoacana no se sometía al proyecto modernizador de la educación superior, impulsado por la federación.

Los universitarios michoacanos se oponían decididamente a la implementación de ese proyecto, porque tenía como base la exclusión de los alumnos y profesores de la política académica y de la gestión en general de la institución, al sustituir al Consejo Universitario como máximo órgano de gobierno, por una Junta; en la supresión de los apoyos a la educación popular como las becas y los albergues estudiantiles; y en el destierro de la ideología socialista, con lo que se pretendía "aristocratizar la enseñanza y ponerla al servicio de la clase dominante" 27 .

Con esta percepción, el estudiantado nicolaita, cuestionaba a Arriaga Rivera, el haber declarado, a su arribo a la gubernatura, que la "hora del trabajo había sonado para Michoacán", y que la universidad no hubiese recibido desde entonces un aumento significativo al subsidio, y que además, ni siquiera se "habían realizado en el Estado obras trascendentes de beneficio social, solamente obras que eran meras 'pantallas' y 'fachadas' que querían ocultar la realidad" 28 .

Como consecuencia del 'congelamiento' del presupuesto, la marcha ascendente que la Universidad había iniciado bajo el rectorado de De Gortari, se detuvo. Varios proyectos y programas de docencia, investigación y difusión de la cultura, no se concretaron; además, algunas de las conquistas obtenidas, como la afiliación al Instituto Mexicano del Seguro Social (IMSS) de los docentes y empleados, se perdieron.

Desde la llegada de Arriaga Rivera al gobierno del Estado, la situación general de la Universidad cambió radicalmente, como ya ha quedado asentado, pero en lo relativo a la asignación de los recursos presupuestales, dicho cambio fue drástico.

Entre septiembre de 1956 y septiembre de 1962, periodo de gobierno del Lic. David Franco Rodríguez, la institución había recibido, en forma de subsidio e

25 "Acta de la sesión del Consejo Universitario", (13 de diciembre de 1965), Archivo Histórico de la Universidad Michoacana (AHUM), Fondo Consejo Universitario, sección secretaría, serie actas, n/f 5 .

26 "Discurso pronunciado por el maestro Ramón Martínez Ocaranza en el acto del día 15 de marzo de 1964, realizado para recordar el sacrificio de Manuel Oropeza García", editado por el Círculo Universitario "Melchor Ocampo", Morelia, 1964 APHB.

27 "La Universidad en peligro", El Nicolaita, año XIV, no. 58, (1965): 1, 6.

28 "Chantaje a la universidad", FEUM, Órgano oficial de la Federación de Estudiantes Universitarios de Michoacán, Época I, s/n, (1964): 1,7 
inversiones la suma de treinta millones de pesos, y del gobierno federal 12270 000 pesos (véase gráfico 1$)^{29}$.

Gráfico 1. Universidad Michoacana, Subsidio 1956-1966

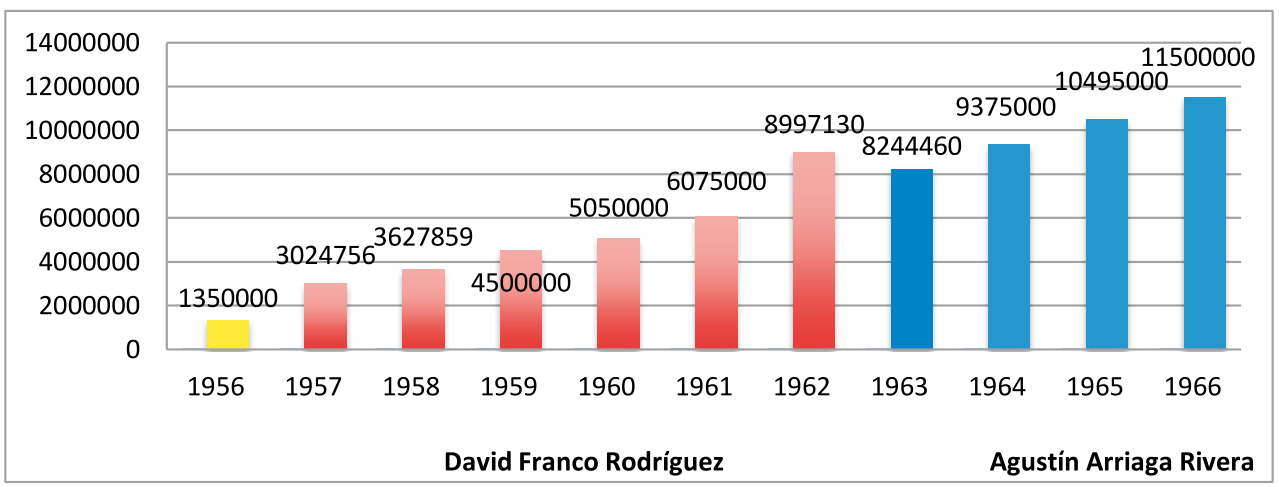

Fuente: elaboración propia, con base en informes de gobierno.

Al inicio del mencionado gobierno, el presupuesto universitario ordinario era de 1350000 pesos, mientras que al término del mismo ascendía a 8906166 pesos, lo que significó un $574 \%$ de incremento, para atender a una población de 4748 alumnos (véase gráfico 2$)^{30}$.

Pero, a raíz del conflicto universitario de febrero-marzo de 1963, el subsidio para la máxima casa de estudios de Michoacán se estuvo entregando de manera irregular, al grado de que hacia el mes de junio, a maestros y empleados no se les habían pagado sus sueldos, y en la caja de la tesorería no había "dinero ni para un sobre"

De esta manera, en la sesión celebrada el 30 de agosto de ese año por el Consejo Universitario Constituyente se aprobó el presupuesto para el ejercicio del $1^{\circ}$ de septiembre al 31 de diciembre, destacando el hecho de que, mientras el total de sus ingresos por concepto de subsidio era de 2641676 pesos, la de sus egresos ascendía a 3571237 pesos, por lo que cerraría el año con un déficit de 929561 pesos $^{32}$.

Frente a la crítica situación, el Consejo Universitario decidió reforzar sus gestiones ante los gobiernos estatal y federal para obtener de ellos un subsidio complementario con el cual cubrir el déficit sin tener que recurrir a "una nueva reducción de plazas y sueldos" ${ }^{\prime 33}$.

Con tal propósito, el rector Bremauntz, acompañado de un grupo de maestros y alumnos, viajó a la ciudad de México en los primeros días del mes de

\footnotetext{
29 "Piedra angular del progreso, la educación universitaria”, La Voz de Michoacán, (1962): 1, 5.

30 "La universidad michoacana alcanzó este año el más alto índice de asistencias escolares”, Ibíd., 1, 12.

31 "Se hace crónica la crisis económica de la universidad", Ibíd., (1963): 1,13.

32 "Aprobó el Consejo el presupuesto de la Universidad Michoacana, Ayer", Ibíd., 1, 13.

33 Ibíd.
} 
noviembre, para entrevistarse con varios funcionarios del gobierno federal, sin obtener resultados satisfactorios ${ }^{34}$.

La nula respuesta llevó al Consejo Universitario a buscar otras soluciones, entre ellas: proponer al gobierno estatal estudiar la posibilidad de crear un impuesto especial en la entidad, destinado a obtener recursos para la universidad, así como la formación de un Patronato Universitario integrado con personalidades representativas de la iniciativa privada y ex alumnos para allegarse fondos por la vía de donativos ${ }^{35}$.

En medio de estas condiciones presupuestales adversas, la Universidad comenzaba el año de 1964, cuando se conocieron las opiniones del secretario ejecutivo de la Asociación Nacional de Universidades e Instituciones de Educación Superior (ANUIES), Lic. Alfonso Ortega Martínez, proponiendo como solución al problema: la supresión en la universidad de la enseñanza secundaria y el cierre de la Facultad de Altos Estudios "Melchor Ocampo", esta última porque a su juicio, "Michoacán produce muchos filósofos" 36 .

Ortega Martínez, actuaba en respaldo y consonancia con la política del gobierno federal de aumentar el presupuesto destinado a la enseñanza técnica en detrimento de la ofrecida en las universidades públicas estatales, que, según su óptica solo formaban profesionistas en el área de las humanidades y de las llamadas carreras liberales. Con el presupuesto más alto de su historia, según rezaban las notas periodísticas, la Secretaría de Educación Pública (SEP), en ese año:

Ampliará la educación técnica para la juventud; ampliará los subsidios al Instituto Politécnico Nacional, a la Universidad Autónoma y a las unidades técnicas de los diferentes estados. Se va a crear un nuevo Instituto Politécnico Regional en Ciudad Juárez; se completarán los laboratorios y talleres de los demás Institutos establecidos. La población escolar que fue de 9, 814 alumnos en 1963, en este año alcanzará 12, 000. Habrá nuevos servicios educativos en 5 Institutos Tecnológicos; se aumentará en 8, 000 alumnos inscritos en los planteles del I.P.N. cuya matrícula fue de 45, 995 en el año pasado $(\text { sic })^{37}$.

El argumento consabido de esta orientación presupuestaria era que:

[...] el actual régimen ha luchado y sigue luchando, porque la juventud estudiosa asista a los Institutos Técnicos, donde se capacita al alumno para las labores que hay que desarrollar en las fábricas y laboratorios. El progreso de todos los países del mundo radica en las escuelas técnicas que han capacitado a las más grandes naciones cuyos adelantos están a la vista.

34 "Más gestiones para allegar fondos a la universidad", Ibíd., 1, 5.

35 "Proponen un impuesto especial para ayudar a la Universidad Michoacana", Ibíd., 1, 12.

36 "Los enemigos de la universidad", (1964): 1, 5.

37 "Lo que hará la SEP en este año", Ibíd., 1, 12. 
Rusia y Estados Unidos, las dos grandes potencias que están a la cabeza del mundo, tienen su fuerza en la técnica que han logrado en sus grandes adelantos que hemos presenciado $(\mathrm{sic})^{38}$.

La definición de esta política en lo relativo al destino preferencial que tendría el subsidio del gobierno de la República en el sector educativo fue expuesta por el Ing. Alejandro Guillot, director general de Enseñanzas Tecnológicas, Industriales y Comerciales de la SEP al inaugurar en Morelia las labores de la Escuela Secundaria Técnica Industrial número 60, anunciando también el acuerdo presidencial de construir en esta ciudad el Instituto Tecnológico Regional ${ }^{39}$, con una erogación de veinte millones de $\operatorname{pesos}^{40}$.

El ex gobernador Arriaga Rivera, en tono jactancioso y triunfalista, se vanagloria en sus memorias de haber logrado sin dificultad en aquel momento el apoyo del gobierno federal para la fundación del Tecnológico en Morelia, sin la oposición de Universidad Michoacana e incluso con la anuencia del rector Bremaunt ${ }^{41}$.

Lo cual no es cierto. Desde su fundación, la Universidad Michoacana tuvo dentro de sus atribuciones el tener bajo su "exclusiva dirección y vigilancia la instrucción y educación en sus elementos superiores" ${ }^{42}$. Esta disposición, con el paso del tiempo, particularmente desde fines de la década de 1920 y durante la de 1930, cuando se dio el movimiento de reforma socialista, provocó una serie de conflictos con aquellas instituciones y planteles que quedaban fuera de la esfera oficial, como las llamadas escuelas libres y particulares -la mayoría regenteadas por el clero-, por la actitud de rechazo que asumieron ante los proyectos y directrices de los gobiernos de Francisco J. Múgica y de Cárdenas. Contra su existencia se pronunciaron y movilizaron constantemente los universitarios nicolaitas ${ }^{43}$.

38 Ibíd. El 1 1. de septiembre de ese año, el presidente de la República, Adolfo López Mateos señaló: "Los estudiantes orientados a una comprensión técnica de la vida son ahora 145 327, de los cuales 45700 cursan en el Politécnico; 10000 en tecnológicos regionales, 300 en el Centro de Capacitación Tecnológica, 640 en 14 nuevas carreras de las normales, 44000 en escuelas industriales y comerciales, 33360 en centros de capacitación para el trabajo industrial y rural y 11327 en los cursos de capacitación del INJM". Adolfo López Mateos, VI Informe de Gobierno, http://www.diputados.gob.mx/cedia/sia/re/RE-ISS-09-06-12.pdf. (25 de agosto, 2017).

39 "Lo que hará la SEP en este Año", La Voz de Michoacán (1964): 1, 12; “Reconocimiento de Michoacán a A.L.M. por el Tecnológico. Su Construcción fincará el Progreso Técnico de Nuestra Entidad”, Ibíd., 1, 12.

40 "El instituto costará 20 millones de pesos y tendrá una capacidad para 700 alumnos", Ibíd., 1, 13. La primera piedra de esta institución educativa fue colocada el 6 de abril de 1964 por el presidente Adolfo López Mateos, el gobernador del Estado Agustín Arriaga Rivera y por el secretario de Educación Pública, Jaime Torres Bodet. La primera etapa fue inaugurada el 30 de septiembre de 1965, y la segunda el 28 de septiembre de 1966, Agustín Arriaga Rivera, La política...como me la enseñaron. Recuerdos añoranzas y realidades de mi vida (México: Editorial Consuelo Sánchez y Asociados, 2005), 138.

41 Ibíd., 137.

42 Ley Orgánica de la Universidad Michoacana, 11 agosto de 1919, Ángel Gutiérrez, (recopilación, textos introductorios y presentación), Leyes Orgánicas de la Universidad Michoacana de San Nicolás de Hidalgo (Morelia: Universidad Michoacana de San Nicolás de Hidalgo, 2001), 17-21.

43 Natalio Vázquez Pallares, presidente del CEN en la sesión del Congreso del Estado celebrada el 4 de agosto de 1931, solicitó a la legislatura la supresión de la Escuela Libre de Derecho, argumentando que: "La Escuela Libre de Derecho que sustentaba la misma ideología del clero pugnaba porque la clase proletaria no se educara, por lo que la Universidad Michoacana protestaba no sólo contra esa escuela, sino también contra el clero que la sostenía". Gerardo Sánchez Díaz, "De Coalcomán al Colegio de San Nicolás. La infancia y los años juveniles de Natalio Vázquez Pallares”, en La Nación dueña de su destino. Vida y obra de Natalio Vázquez Pallares, eds. Mario Nájera Espinoza, Gerardo Sánchez Díaz y Verónica Oikión Solano (Guadalajara: U de G/El Colegio de Michoacán/ Universidad Michoacana de San Nicolás de Hidalgo, 2007), 43-50; véase también Miguel Ângel Gutiérrez López, En los límites de la 
Este conflicto se mantuvo latente aunque con menos intensidad en las siguientes dos décadas. En realidad, los vacíos legales en la materia, permitieron consolidar los proyectos educativos de los sectores tradicionales en el área de los estudios comerciales y hasta normales. Pero la conflictividad se reavivó durante los años sesenta como resultado del ambiente ideológico producido por la Guerra Fría, recrudeciéndose el enfrentamiento entre las escuelas privadas de corte clerical y la Universidad Michoacana, al reclamar ésta la exclusividad, vigilancia y control de la educación superior en el Estado, para lo cual haría más estricta la incorporación de dichos planteles ${ }^{44}$.

El rector Bremauntz en su informe de labores correspondiente al año lectivo 1964-1965, advertía, al tiempo que cuestionaba la consolidación de tales establecimientos:

[...] Los sectores de derecha han obtenido notorias y manifiestas ventajas en el ramo educacional, debido a la debilidad, indiferencia o tolerancia claudicante de algunos de nuestros mandatarios e igualmente por la abstención culpable de muchos revolucionarios, originada por la desunión, desorganización, oportunismo o insinceridad.

El clero y los elementos derechistas han fundado numerosos establecimientos educativos de todos los grados en flagrante violación constitucional y, por otra parte, en algunas universidades estatales o descentralizadas, como en diversos planteles oficiales actúan numerosos maestros y catedráticos contrarrevolucionarios. Por ello hemos afirmado y afirmaremos que la juventud mexicana, que es la que debe continuar el programa y la obra de la Revolución, se encuentra en estos tiempos, y en gran parte, en manos de dichos elementos ${ }^{45}$.

Para revertir esta situación, el Consejo Universitario aprobó el 10 de julio de 1964 el Reglamento para la Incorporación de Institutos y Escuelas a la Universidad Michoacana de San Nicolás de Hidalgo, que literalmente "paró en seco todo reconocimiento oficial de los estudios hechos en establecimientos confesionales", lo que se convertiría en otro motivo de distanciamiento y enfrentamiento entre la institución y el régimen arriaguista ${ }^{46}$.

De acuerdo con Pablo G. Macías, a raíz de la aprobación de este reglamento la Junta de Gobierno y el rector fueron objeto "de los más rabiosos ataques de organizaciones fantasmas, de elementos retrógrados y de líderes facciosos de Michoacán, en cuyas actitudes se veía la línea del clero y el beneplácito del gobierno del estado" ${ }^{47}$.

autonomía. La reforma socialista en la Universidad Michoacana, 1934-1943 (Zamora: El Colegio de Michoacán, 2011 ), 54-72.

44 Adrián Luna Flores, "Las escuelas particulares de comercio en Michoacán y su lucha por el reconocimiento oficial, 1920-1960", Río de Papel, no. 23 (2015): 57.

45 Alberto Bremauntz, Informe de labores, 1964-1965 (Morelia: Universidad Michoacana de San Nicolás de Hidalgo, 1966), 12-13.

46 Pablo G. Macías Guillén, Luces y sombras.Testimonios nicolaitas (Morelia: Universidad Michoacana de San Nicolás de Hidalgo, 1981), 188-187.

47 Ibíd., 188. 
Este conflicto fue aprovechado por el grupo de choque que el gobierno estatal tenía infiltrado en la universidad, mismo que el 30 de septiembre de ese año, durante el desfile cívico-militar conmemorativo del natalicio del generalísimo José $\mathrm{M}^{a}$ Morelos -héroe epónimo de la independencia-, agredió a jóvenes de los colegios particulares que participaban en el homenaje, con el perverso objetivo de culpar a los universitarios del ataque, como así ocurrió. La Voz de Michoacán, dirigida por José Tocaven, vocera incondicional del gobernador, "aseveró que los agresores habían sido los nicolaitas", y aunque las autoridades universitarias protestaron por la acusación sin fundamento, la gente común dio crédito a las calumniosas notas incriminatorias, manifestando su indignación ${ }^{48}$.

Así, el doble discurso de Arriaga Rivera, sumía a la universidad en la incertidumbre financiera, y a pesar de que esta participaba del esfuerzo por reforzar la formación de técnicos para las áreas industriales, no recibiría el apoyo presupuestal que solicitaba porque, como ya lo hemos señalado su proyecto de una educación popular y nacionalista chocaba con el proyecto modernizador del Estado mexicano.

Por otro lado, las presiones para que la institución se desligara de la educación secundaria eran muy fuertes. El gobierno federal hizo la propuesta de suprimir la Escuela Secundaria Nocturna para Trabajadores, como condición para aumentarle la cantidad de cien mil pesos a su presupuesto. Pero este solo sería el comienzo porque estaban contempladas la clausura de las secundarias Varonil y Femenil ${ }^{49}$.

Una propuesta más consistía en suspender las labores de la Escuela de Ingeniería Industrial a partir de 1965, para obtener con ello el ahorro de un millón de pesos y destinarlos a la compra de material, instrumentos y equipos para los laboratorios y talleres de otras escuelas ${ }^{50}$.

Además de estas medidas que formaban parte del plan preparado por Ortega Martínez, como condición necesaria para aumentar el subsidio federal a la Universidad Michoacana ${ }^{51}$, se pretendía el cierre de la Escuela Popular de Bellas Artes, y de las recientemente creadas facultades de Agrobiología y Altos Estudios "Melchor Ocampo", así como de la Preparatoria de Uruapan ${ }^{52}$.

La educación media superior impartida por la universidad era particular objeto de ataques, pues se argumentaba, que este nivel educativo debía estar única y exclusivamente controlado por la SEP, porque en todo caso, decían los funcionarios de esta dependencia federal y de la ANUIES, ese gasto debía ahorrárselo la institución e invertirlo en otras carreras o en el último de los casos, ahorrárselo al propio Estado ${ }^{53}$.

\footnotetext{
$48 \quad$ Ibíd., 179.

49 "La conspiración de los genios. El plan de Ortega Martínez en marcha", FEUM, Órgano Oficial de la Federación de Estudiantes Universitarios de Michoacán, época I, s/n, (1964): 2, 3.

50 Ibíd.

51 En la Universidad Autónoma de Puebla bautizaron a ese funcionario de la ANUIES, como "el ave negra”, ya se podrá deducir por qué razón, "Antecedentes del problema de la Universidad Michoacana de San Nicolás de Hidalgo".

52 "Chantaje a la universidad".

53 Ibíd.
} 
Pero este chantaje no fue aceptado por los universitarios, quienes resistieron los embates y las presiones económicas, logrando por el momento mantener en su seno la educación secundaria y la media superior, y evitando la clausura de alguna de sus escuelas del nivel licenciatura, e incluso, en medio de las condiciones adversas que significaba el déficit presupuestal, asegurar la viabilidad de ellas, como el caso de la Escuela de Ingeniería Industrial, la cual se afianzó bajo la perspectiva de que, de acuerdo a lo planeado por la Comisión del Balsas, para 1965, la planta siderúrgica que aprovecharía los yacimientos ferrosos de la región denominada "Las Truchas" entraría en plena producción y requeriría para su operación de una gran cantidad de personal técnico calificado en esa rama $^{54}$.

Durante el año de 1963, la Universidad Michoacana, había ejercido un presupuesto total de 8244460 pesos, de los cuales el gobierno del estado aportó 3650 000 pesos, el federal 4245000 pesos, mientras que por ingresos propios obtuvo 332460 pesos y por donativos 17000 pesos $^{55}$. Al respecto, las autoridades universitarias señalaban que, de acuerdo a la población estudiantil atendida: 5015 alumnos, el presupuesto por alumno era de 1743 pesos, uno de los más bajos de las universidades públicas del país, solo por encima de la Universidad de Nuevo León, cuyo costo era de 1643 pesos y de la de Campeche que era el más bajo con 430 pesos por alumno. Para el nuevo año escolar, la Comisión de Hacienda, la rectoría y la auditoría, sometieron a consideración del Consejo Universitario un proyecto parcial que contemplaba la erogación, en el periodo comprendido del $1^{\circ}$ de febrero de 1964 al 31 de enero de 1965, de 8704000 pesos $^{56}$. Lo anterior sin incluir los recursos necesarios para el funcionamiento de la Comisión de Investigación Científica, el pago de becas a los alumnos y partidas para otros ramos, lo que elevaría las necesidades presupuestales a 12914202 pesos $^{57}$.

Finalmente, el presupuesto aprobado para dicho año fue de 9375000 pesos, de los cuales el gobierno estatal aportaría 4050000 pesos, de los que se descontarían 500000 pesos que dicho gobierno había facilitado a la institución en el mes de diciembre anterior, para cubrir el pago de salarios de fin de año, a cuenta del subsidio de $1965^{58}$.

Entre lo que solicitó y requería la universidad: 12914202 pesos y lo aprobado para el año de 1964 existía un déficit presupuestal de 3539202 pesos, por lo que, el Consejo Universitario tomó el acuerdo de distribuir el mencionado ingreso para satisfacer las partidas esenciales, pero aun así resultaban absolutamente

54 “3, 275 Técnicos Industriales y Obreros se requieren para la Siderúrgica Las Truchas", La Voz de Michoacán, (1963): 1, 12; "No desaparecerá la Escuela de Ingeniería Industrial de la Universidad Michoacana”, Ibíd., 1, 13.

55 "Es de los más bajos el presupuesto por alumno en la U.M. Doce millones de pesos necesita la universidad para el presente ciclo", Ibíd., (1964): 1, 5.

56 Ibíd.

57 "El gobernador asistió a la lectura del informe del rector A. Bremauntz", Ibíd., 1, 12.

58 "Continúa siendo difícil la situación económica de la Universidad Estatal", (1965): 1, 13; "El gobernador asistió a la lectura del informe del rector A. Bremauntz", Ibíd. 
indispensables 1665957 pesos, "sin cuya cantidad era verdaderamente imposible el eficaz funcionamiento de la casa de estudios" ${ }^{\prime 59}$.

Las gestiones realizadas ante los gobiernos estatal y federal, por parte del rector, recibía la reiterada y desalentadora respuesta burocrática de que: "se están dando los pasos necesarios para lograr lo más pronto posible el aumento del subsidio", por lo que ante el agobiante problema, fue retomado el proyecto de constituir el Patronato Universitario, el cual comenzó a ser promovido por el Dr. Salvador Franco López, como presidente de la Asociación de Ex alumnos Universitarios y por la "Casa de Michoacán" en el D.F., presidida por el Lic. David Franco Rodríguez ${ }^{60}$.

A mediados de enero de 1965, el Consejo Universitario formuló el anteproyecto de presupuesto de ese año, mismo que ascendía en números redondos a la cantidad de 15000000 de pesos ${ }^{61}$, de los cuales solamente podría disponer de 10495000 pesos, correspondientes a los subsidios federal y estatal e ingresos propios $^{62}$.

Nuevamente el rector Bremauntz viajó a la ciudad de México para gestionar más recursos ante el gobierno federal y entrevistarse con los directores de Petróleos Mexicanos (PEMEX) y de la Comisión Federal de Electricidad (CFE) con el fin de conseguir la donación del equipo necesario para la instalación de los laboratorios y talleres de las carreras de Ingeniería Mecánica, Eléctrica y Química ${ }^{63}$.

Un mes después, el Lic. Agustín Yáñez, secretario de Educación Pública, le notificó que de acuerdo con el programa aprobado por la presidencia de la República para la ampliación de subsidios extraordinarios a las universidades de provincia, le correspondía a la Universidad Michoacana, tan solo el aumento de 100000 pesos $^{64}$.

Mientras tanto, una mínima parte del crónico déficit presupuestario era solventado a 'cuentagotas' por el gobierno estatal, que solo respondía ante situaciones extremadamente urgentes como el otorgamiento de un subsidio extraordinario de 59747 pesos, que serían nuevamente destinados al pago de salarios con motivo del fin de año ${ }^{65}$.

En medio de estas dramáticas condiciones económicas, algunas personas, movidas por altruismo o en descargo de su conciencia, como el señor Arnulfo Ávila ex tesorero del gobierno del Estado, legó a la universidad la cantidad de 1500000 pesos. La donación debería ser destinada única y exclusivamente para la construcción del Auditorio Universitario. Esta era una añeja necesidad de la institución y, desde luego comenzó a planearse su edificación en el terreno locali-

\footnotetext{
59 "Continúa siendo difícil...

60 Ibíd., 1, 13; “Patronato universitario”, Ibíd. (1964): 1, 5.

61 “Más de 15 millones presupuesta para este año la Universidad”, Ibíd. (1965): 1, 12.

62 “Cinco millones requiere la U.M. para cumplir con su función”, Ibíd., 1, 13.

63 "Importantes gestiones hará el rector ante dependencias federales", Ibíd., 1, 12.

64 "Aprueban un aumento de solo 100 mil pesos para la Universidad", Ibíd., 5.

65 "Subsidio extraordinario de 60 mil pesos a la Universidad", Ibíd., 1, 5.
} 
zado frente al Colegio de San Nicolás, el cual había sido cedido por el presidente de la República, Gral. Cárdenas, precisamente para dicho objeto ${ }^{66}$.

En estas circunstancias, el anteproyecto de presupuesto elaborado por la Comisión de Hacienda del Consejo Universitario para el año lectivo de 1966 ascendía, en números redondos, a la cantidad de dieciocho millones de pesos, mismo que fue presentado al gobernador Arriaga Rivera en una reunión que sostuvieron con él un grupo de profesores y alumnos encabezados por el rector. Bremauntz, al hacer la relación de las necesidades que tenía la universidad, señaló que estas no podrían solventarse con "el presupuesto actual de poco más de diez millones de pesos, lo cual ha detenido considerablemente la reforma académica, impidiendo en todos los órdenes la evolución científica, técnica y cultural que demanda una Universidad Moderna". Ante ello el gobernante se limitó a prometer el aumento del subsidio del Estado en la medida de lo posible $\mathrm{y}$ "apoyar las gestiones para lograr que el gobierno federal haga otro tanto" ${ }^{\prime 67}$.

Los vagos ofrecimientos que hizo el gobernador, se concretaron en un aumento al presupuesto del Estado de tan solo 600000 pesos. Es decir la universidad contaría con un presupuesto estatal de cinco millones de pesos, mientras que el gobierno federal, no solo respondería en la misma forma, sino que retrasaría el envío de los recursos asignados ${ }^{68}$.

Gráfico 2. Universidad Michoacana. Porcentaje comparativo de aumento al subsidio entre las administraciones estatales de David Franco R. y Agustín Arriaga R.

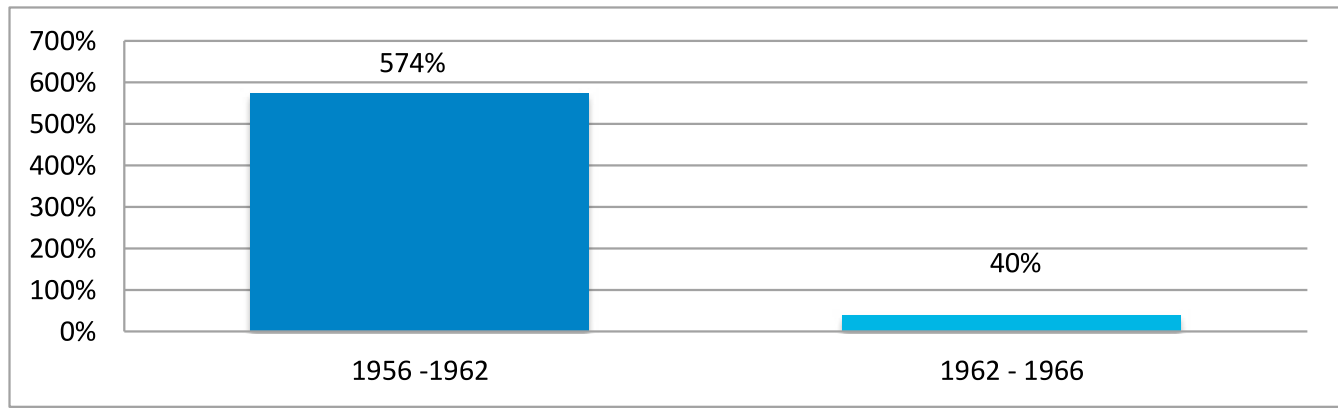

Fuente: elaboración propia con base en informes de gobierno

\section{6. 'Remando contracorriente', la universidad no se estanca}

Sin embargo, aun con las limitaciones que representaba el raquítico presupuesto universitario, bajo el rectorado de Bremauntz se dieron significativos

66 "Legan millón y medio de pesos a la U.M., Ibíd., 5.

67 "Aumento de subsidio para la Universidad", Ibíd., 1, 12.

68 “600 mil pesos más otorga el gobierno estatal a la U.M., Ibíd. (1966): 1, 13; “Otorga el gobernador Arriaga Rivera un préstamo de cien mil pesos a la Universidad”, Ibíd., 1, 12. 
avances materiales y académicos en la Universidad Michoacana. Se reformó el plan de estudios de la Facultad de Altos Estudios, se integraron en una sola las carreras de Ciencias Físicas y Matemáticas, que funcionaban como especialidades separadas ${ }^{69}$, y se aprobó en esta misma Facultad la creación de la Licenciatura en Letras Españolas, la cual, como quedó anotado líneas atrás, no llegó a funcionar ${ }^{70}$. Igualmente, después de someterse a revisión los planes y programas de estudio de la Escuela Popular de Bellas Artes, se implementaron en ella las modalidades de instrumentista, pintor, escultor, grabador y ejecutante de danza clásica $^{71}$.

En la Escuela de Ingeniería Industrial, después de aceptarse la petición de la Sociedad de Alumnos, se creó, el $1^{\underline{0}}$ de julio de 1965, en forma independiente, la Facultad de Ingeniería, con especialidades en Mecánica, Eléctrica y Química (FIMEQ). Proceso parecido se dio en la Escuela de Contabilidad y Administración, donde se suprimió la Secundaria Comercial para dar paso a la carrera de Técnico en Contabilidad y Administración con duración de tres años ${ }^{72}$; y en el nivel medio superior, por iniciativa del Consejo Técnico de la Facultad de Altos Estudios "Melchor Ocampo", se aprobó formalmente la creación de las Escuelas Secundaria y Preparatoria Nocturnas para Trabajadores que funcionarían con la participación gratuita de profesores de dicha facultad y que serviría al mismo tiempo para la práctica de la formación docente de sus alumnos. De igual forma, el Consejo Universitario, aprobó la creación del Centro de Investigaciones Sociales de la Universidad Michoacana, que infortunadamente quedaría en el papel, así como la licenciatura en Letras Españolas, merced al crónico déficit presupuestal ${ }^{73}$.

Para fortalecer el campo de la investigación científica, se consiguió el apoyo del Instituto Nacional de la Investigación Científica, consistente en la donación de un laboratorio de electrónica para la Escuela de Ingeniería Industrial y la Facultad de Altos Estudios "Melchor Ocampo"74.

En el nivel medio superior se crearon doce nuevas secciones para los diversos bachilleratos ${ }^{75}$, pero el acuerdo de estudiar la posibilidad de implantar el bachillerato de tres años quedaría solo en el intento, dadas las difíciles circunstancias económicas por las que atravesaba la universidad ${ }^{76}$.

En lo referente a la regulación de las actividades universitarias, el Consejo Universitario aprobó el Reglamento General del Profesorado, así como el regla-

\footnotetext{
69 Bremauntz, Setenta años de mi vida, 12.

70 "Acta (17 de junio de 1966), Ibíd., n/f 4.

71 "Acta (29 de noviembre de 1963), Ibíd., n/f 6.

72 "Acta (1 $1^{\circ}$. de julio de 1964), Ibíd., n/f 4; “El gobernador asistió a la lectura...

73 "Acta (17 de junio de 1966), Ibíd., n/f 4.

74 “Acta (28 de enero de 1966), Ibíd., n/f 6-9; “Laboratorio electrónico para la U.M. Importante donación”, La Voz de Michoacán, (1963): $1,12$.

75 “El presupuesto de la Universidad llegará a más de 12 millones con la ayuda federal”, Ibíd. (1964): 1. 12.

76 "Acta (27 de enero de 1964), Ibíd., n/f 5.
} 
mento que normaría las relaciones entre la institución y sus trabajadores administrativos y manuales ${ }^{77}$.

En el renglón de la difusión cultural, el departamento encargado de esta actividad editó varias obras, revistas y periódicos estudiantiles, así como otras publicaciones. Por lo que respecta a la extensión universitaria, la institución fiel a su tradición popular, retomó la organización de las brigadas culturales, mismas que integraron principalmente alumnos y maestros de las escuelas del área de la salud e ingeniería, operando en las poblaciones de Las Mesas, Irapeo, Jaripeo, Uruétaro, Cuitzeo del Porvenir, Atapaneo y algunas comunidades de la meseta tarasca ${ }^{78}$.

La vinculación y el intercambio académico con otras instituciones de educación superior, también fue cultivada. El rector Bremauntz, motivado por la orientación socialista de la universidad nicolaita, estableció relaciones culturales y académicas con universidades cubanas. Producto de esta relación, la embajada de Cuba en México otorgó tres becas a la FEUM para aquellos jóvenes que quisieran ir a estudiar a la isla ${ }^{79}$, haciéndose efectivas dos: Víctor Olmedo del Colegio de San Nicolás y Luis Eduardo Guerra de la Facultad de Contabilidad y Administración ${ }^{80}$.

El embajador de Cuba en México, Dr. Joaquín Hernández Armas, visitó la Universidad Michoacana en dos ocasiones durante la administración del rector Bremauntz, ofreciendo sendas conferencias en el teatro universitario "José Rubén Romero" el 6 de mayo y el 21 de agosto de 1964. En la primera de ellas, equiparó los anhelos cubanos con la esperanza de los estudiantes nicolaitas, que "ha sido cuna de grandes hombres que han luchado por la libertad", manifestando que le causaba gran emoción visitar a la institución que "por más de cuatrocientos años de existencia, había sostenido una lucha digna en defensa de las clases desheredadas y por la educación social de México, lucha que sigue presente, a pesar de las embestidas de las fuerzas oscurantistas que continuamente buscan minar sus bases revolucionarias" 81 . Señaló también que "a pesar de las provocaciones y agresiones de los Estados Unidos de América, el pueblo cubano no retrocederá un paso", y que confiaba en el apoyo de todos los mexicanos. Dicho esto, uno de los asistentes le manifestó: "a nombre de los estudiantes de la Universidad Michoacana el más amplio y decidido apoyo en su lucha, a la hermana República de Cuba" ${ }^{82}$.

El rector, atendiendo la invitación que le hicieran las Universidades de La Habana y del Oriente, visitó Cuba en julio de 1964. A su regreso, el 11 de agosto, dictó una conferencia sobre "El desarrollo social y cultural de la República

\footnotetext{
77 "Acta (17 de junio de 1966), Ibíd.

78 Bremauntz, Setenta años de mi vida, 14.

79 "Ofrece becas a estudiantes de aquí el gobierno revolucionario cubano", La Voz de Michoacán, (1964): 5.

80 "Salen hoy a Cuba dos estudiantes", Ibíd., 5.

81 "Pláticas en la U.M. del embajador cubano", Ibíd., 1, 12.

82 "Informe del Director Federal de Seguridad, Manuel Rangel Escamilla" (6 de mayo de 1964), AGN/IPS, Versión Pública Elí de Gortari, legajo 1/4; "El embajador de Cuba dará aquí una conferencia”, La Voz de Michoacán, (1964): 5.
} 
Socialista Cubana" en el teatro universitario, donde exaltó los aspectos legislativos fundamentales del periodo de transición del capitalismo al socialismo que vivía la Revolución cubana: la Ley de Nacionalización, mediante la cual se "han expropiado las empresas industriales y comerciales"; la Ley de Reforma Bancaria, por la que pasó a manos del Estado el manejo del sistema bancario; la Ley de la Reforma Agraria, fundamental para el proceso revolucionario, por la cual se "ha destruido el latifundio, nacionalizado la tierra y entregada a los campesinos"; y la Ley de la Reforma Urbana, que "ha permitido una gran transformación de las ciudades, convirtiendo en dueños a los inquilinos" ${ }^{\prime 3}$.

En correspondencia, Bremauntz entregó al Dr. Hernández Armas, durante un solemne acto, celebrado en el aula magna del Colegio de San Nicolás, una estatua de Emiliano Zapata elaborada por el escultor Raúl García, maestro de la Escuela Popular de Bellas Artes, como "un reconocimiento a la lucha heroica del pueblo cubano" ${ }^{84}$.

La estatua fue develada en La Habana en presencia del rector Bremauntz el 10 de septiembre de 1965, como parte de los eventos de la Semana de México en $\mathrm{Cuba}^{85}$. Al día siguiente, la Universidad Michoacana fue objeto de un homenaje realizado en el aula magna de la Universidad de La Habana ${ }^{86}$.

Por su parte, en solidaridad con la joven república cubana, la máxima casa de estudios de Michoacán organizó la Semana Cultural Cubana-Mexicana, que se desarrolló del 18 al 23 de abril de 1966, con un programa que incluyó representaciones teatrales, danza, conciertos, documentales, recitales y conferencias ${ }^{87}$.

Durante el mes de junio, la rectoría de la universidad a través del departamento de Difusión Cultural, organizó un ciclo de conferencias titulado "La política exterior de México y la de los países socialistas", mismo que se llevó a cabo en el teatro "José Rubén Romero" 88 . Al tiempo que se dictaban estas conferencias, se montaron dos exposiciones: una sobre grabado chino en las galerías de la Escuela Popular de Bellas Artes, y otra sobre la Unión de Repúblicas Socialistas Soviéticas (URSS) en el salón de exposiciones del teatro universitario ${ }^{89}$.

Las actividades anteriormente reseñadas, se llevaron a cabo, con enormes limitaciones, por la falta de apoyos económicos a la universidad de parte, tanto del gobierno estatal como del federal. En ese sentido, una de las principales demandas del reagrupado movimiento estudiantil nicolaita era el aumento al subsidio universitario y el otorgamiento de la "verdadera autonomía", pues comenzaban a comprender que esta sería el medio para asegurar que la institu-

\footnotetext{
83 "En Cuba se está llevando a cabo el gran experimento social de América: Bremauntz", Ibíd., 5.

84 "Colocarán en La Habana una estatua de Zapata que donará la Universidad local", Ibíd., 1, 12.

85 Alberto Bremauntz, México y la revolución socialista cubana (Morelia: Fimax Publicistas, 1966), 73.

86 Ibíd., 75-77.

87 "Semana cultural cubana-mexicana", Vida Nicolaita, época I, año III, nº 23 (1966): 23; véase también, Lucio Rangel Hernández, "La Universidad Michoacana, el movimiento estudiantil universitario michoacano y la solidaridad con la Revolución cubana", Universidad Michoacana. Revista trimestral de ciencia, arte y cultura $\mathrm{n}^{\circ}$. 13, (1994): 133.

88 "Informe del agente N.M.M." (10 de junio de 1966), AGN/IPS, Caja 439.

89 Ibíd.
} 
ción: "cumpla con su función social e impedir que sea puesta al servicio de las clases dominantes nacionales y del imperialismo norteamericano" ${ }^{\prime 90}$.

Para mediados de 1966, varias organizaciones estudiantiles comenzaron a movilizarse ante la cercanía de la sucesión rectoral. En esta coyuntura, la FEUM como la más representativa de las organizaciones estudiantiles nicolaitas, se planteó como parte de su programa de trabajo -que hizo llegar a los aspirantes a la rectoría-, luchar abiertamente por la desaparición de la Junta de Gobierno, y por reformar la Ley Orgánica vigente para recuperar la orientación socialista contenida en la Ley Orgánica de $1961^{91}$.

Además de estos objetivos políticos, la FEUM se proponía pugnar por: abrir la preparatoria número dos en la ciudad de Morelia, montar la imprenta y editorial universitaria, reorganizar el Instituto de la Población -creado formalmente en 1962, pero que no había entrado en operación-, organizar el Departamento Pedagógico, abrir una Casa del Estudiante en la ciudad de Uruapan, mejorar los servicios en los albergues que ya existían, y aumentar el número y la cuantía de las becas otorgadas a los estudiantes de escasos recursos económicos ${ }^{92}$.

La FEUM, consciente de que para el logro de estos propósitos y en general para el mejoramiento material y académico de su casa de estudios era indispensable el aumento al subsidio universitario, se preparaba para arrancarle al Estado los recursos necesarios ${ }^{93}$.

\section{CONCLUSIÓN}

Como hemos demostrado, la represión violenta que sofocó la protesta estudiantil contra la derogación de la Ley Orgánica de 1961 permitió la imposición de los miembros de la Junta de Gobierno -figura creada en la nueva legislación- y de Alberto Bremauntz como nuevo rector; sin embargo, dados los antecedentes de la mayoría de los integrantes de la mencionada Junta y sobre todo del rector, la institución no se supeditó a los designios del gobernador Arriaga Rivera, manteniendo su orientación popular y nacionalista frente a los intentos de imponerle el modelo educativo empresarial importado por el Estado mexicano desde la administración federal de Ávila Camacho. Por ello, la Universidad Michoacana fue sometida a un régimen de hostilidad y represión materializado primordialmente en el congelamiento de su presupuesto, pero utilizando a la par muchos otros instrumentos y recursos de coerción, como la cooptación de algunos de sus liderazgos juveniles y la infiltración de un grupo de choque entre los universitarios, que por medio de prácticas porriles trató de impedir la

90 J. Luis Reynoso Hernández, "Autonomía universitaria”, El Nicolaita, año XIII, nº. 54, (1965): 2, 3; "La Junta de Gobierno y la Universidad”, FEUM, Órgano de la Federación de Estudiantes Universitarios de Michoacán, nº. 4, Morelia, 15 de junio (1966): 1, 3.

91 "Postulados de la Educación Universitaria y Programa Básico de Trabajo de la FEUM" (Morelia, abril, de 1966), APHB.

92 Ibíd.

93 Ibíd. 
reorganización y la reanimación del movimiento estudiantil que se oponía a la imposición de dicho modelo educativo.

Es decir, ni el congelamiento del subsidio, ni la cooptación, ni las prácticas porriles del grupo de choque y las acciones represivas emprendidas contra los auténticos liderazgos juveniles, impidieron la recuperación de los principales organismos estudiantiles: la FEUM y el CEN; estas entidades encabezaron hacia el final del rectorado de Bremauntz la reagrupación y la reanimación del movimiento estudiantil universitario que comenzó a exigirle al Estado la asignación de los recursos presupuestarios que requería su casa de estudios no únicamente para su desarrollo material y académico, sino para seguir impulsando el proyecto de universidad popular y nacionalista.

Finalmente ante la férrea resistencia de la mayoría de los estudiantes y profesores nicolaitas, encabezados por el rector, el Estado mexicano autoritario tendría que echar mano del recurso de la violencia, en octubre de 1966, para doblegarla e imponerle a la Universidad Michoacana los principios modernizantes educativos tendentes a adecuar las instituciones de educación superior a las necesidades del proyecto industrializador puesto en marcha en México desde el periodo presidencial de Ávila Camacho.

\section{FUENTES}

"Atraco priísta". El Nicolaita época XI, no 47 (1963).

“Apareció en el D. F. el líder A. Talamantes". La Voz de Michoacán (1964).

"Aprobó el Consejo el presupuesto de la Universidad Michoacana, ayer". La Voz de Michoacán (1963).

"Aprueban un aumento de sólo 100 mil pesos para la Universidad". La Voz de Michoacán (1965).

"Aumento de subsidio para la Universidad". La Voz de Michoacán (1965).

Archivo General de la Nación (AGN), Ciudad de México - México. Fondo Dirección General de Investigaciones Políticas y Sociales, Caja 455.

Archivo General de la Nación (AGN), Ciudad de México - México. Fondo Dirección General de Investigaciones Políticas y Sociales, Caja 456.

Archivo General de la Nación, (AGN), Ciudad de México - México. Fondo Dirección General de Investigaciones Políticas y Sociales, Versión Pública Elí de Gortari, legajo 1/4.

Archivo General de la Nación, (AGN), Ciudad de México - México. Fondo Dirección General de Investigaciones Políticas y Sociales, Caja 439.

Archivo Histórico de la Universidad Michoacana (AHUM), Morelia - México. Fondo Consejo Universitario, sección secretaría, serie actas, $\mathrm{n} / \mathrm{f} 5$.

Archivo Histórico de la Universidad Michoacana (AHUM), Morelia - México. Fondo Consejo Universitario, sección secretaría, serie actas, $\mathrm{n} / \mathrm{f} 4$.

Archivo Histórico de la Universidad Michoacana (AHUM), Morelia - México. Fondo Consejo Universitario, sección secretaría, serie actas, $\mathrm{n} / \mathrm{f} 6$.

Archivo Histórico de la Universidad Michoacana (AHUM), Morelia - México. Fondo Consejo Universitario, sección secretaría, serie actas, $\mathrm{n} / \mathrm{f} 4$.

Archivo Histórico de la Universidad Michoacana (AHUM), Morelia - México. Fondo Consejo Universitario, sección secretaría, serie actas, n/f 6-9.

Archivo Histórico de la Universidad Michoacana (AHUM), Morelia - México. Fondo Consejo Universitario, sección secretaría, serie actas, $\mathrm{n} / \mathrm{f} 5$.

Archivo Particular de Hiram Ballesteros Olivares (APHB), Morelia - México. “Declaración de la Juventud Comunista de México al Estudiantado y al pueblo de México”, Morelia, 25 de agosto de 1964.

Archivo Particular de Hiram Ballesteros Olivares (APHB), Morelia - México. “Discurso pronunciado por el maestro Ramón Martínez Ocaranza en el acto del día 15 de marzo de 1964, realizado para recordar el sacrificio de Manuel Oropeza García”, editado por el Círculo Universitario “Melchor 
Ocampo", Morelia, 1964.

"Cinco millones requiere la U.M. para cumplir con su función". La Voz de Michoacán (1965).

"Colocarán en La Habana una estatua de Zapata que donará la Universidad Local”. La Voz de Michoacán (1964).

"Continúa siendo difícil la situación económica de la Universidad Estatal”. La Voz de Michoacán (1965).

"Chantaje a la Universidad". FEUM, Órgano oficial de la Federación de Estudiantes Universitarios de Michoacán época I, s/n (1964).

Entrevista a Olmedo Ortiz, Cuauhtémoc, Morelia (Michoacán), 1º de febrero de 1991.

Entrevista a Mejía González, Adolfo, Morelia (Michoacán), 23 de agosto de 1994.

Entrevista a Aguilar Talamantes, Rafael Ignacio, Ciudad de México, 27 de octubre de 2015.

"Es de los más bajos el presupuesto por alumno en la U. M. Doce millones de pesos necesita la Universidad para el presente ciclo". La Voz de Michoacán (1964).

“El Instituto costará 20 millones de pesos y tendrá una capacidad para 700 alumnos". La Voz de Michoacán (1964).

“El gobernador asistió a la lectura del informe del rector A. Bremauntz". La Voz de Michoacán (1964).

"El embajador de Cuba dará aquí una conferencia". La Voz de Michoacán (1964).

"En Cuba se está llevando a cabo el gran experimento social de América: Bremauntz". La Voz de Michoacán (1964).

Fabela, Javier. “'Tijerazo' en 40 dependencias”. La Voz de Michoacán (2016).

"Intervención del gobierno en la Universidad". FEUM, Órgano de Difusión de la Federación de Estudiantes Universitarios de Michoacán época I, $\mathrm{n}^{\circ} 1$ (1964).

"Importantes gestiones hará el rector ante dependencias federales". La Voz de Michoacán (1965).

"La Universidad en peligro". El Nicolaita año XIV, n 58 (1965).

"La Universidad Michoacana alcanzó este año el más alto índice de asistencias escolares". La Voz de Michoacán (1962).

"La conspiración de los genios. El plan de Ortega Martínez en marcha". FEUM, Órgano Oficial de la Federación de Estudiantes Universitarios de Michoacán época I, s/n (1964).

“La Junta de Gobierno y la Universidad”. FEUM, Órgano de la Federación de Estudiantes Universitarios de Michoacán $\mathrm{n}^{\circ} 4$ (1966).

"Legan millón y medio de pesos a la U. M.". La Voz de Michoacán (1965).

"Los enemigos de la Universidad". La Voz de Michoacán (1964).

"Lo que hará la SEP en este año". La Voz de Michoacán (1964).

"Más gestiones para allegar fondos a la Universidad". La Voz de Michoacán (1963).

"Más de 15 millones presupuesta para este año la Universidad". La Voz de Michoacán (1965).

"Neofacismo en la Universidad". FEUM, Órgano de Difusión de la Federación de Estudiantes Universitarios de Michoacán época I, nº 1 (1964).

"No desaparecerá la Escuela de Ingeniería Industrial de la Universidad Michoacana". La Voz de Michoacán (1963).

"Piedra angular del progreso, la educación universitaria". La Voz de Michoacán (1962).

"Otorga el gobernador Arriaga Rivera un préstamo de cien mil pesos a la Universidad". La Voz de Michoacán (1966).

“Ofrece becas a estudiantes de aquí el gobierno revolucionario cubano”. La Voz de Michoacán (1964).

"Patronato universitario". La Voz de Michoacán (1964).

"Proponen un impuesto especial para ayudar a la Universidad Michoacana". La Voz de Michoacán (1963).

"Pláticas en la U. M. del embajador cubano". La Voz de Michoacán (1964).

Reynoso Hernández, J. Luis. “Autonomía universitaria”, El Nicolaita año XIII, no 54 (1965).

"Reconocimiento de Michoacán a A. L. M. por el Tecnológico. Su construcción fincará el progreso técnico de nuestra entidad". La Voz de Michoacán (1964).

"Salen hoy a Cuba dos estudiantes". La Voz de Michoacán (1964).

“600 mil pesos más otorga el gobierno estatal a la U. M.". La Voz de Michoacán (1966).

“Se hace crónica la crisis económica de la Universidad". La Voz de Michoacán (1963).

"Subsidio extraordinario de 60 mil pesos a la Universidad". La Voz de Michoacán (1965).

"275 técnicos industriales y obreros se requieren para la siderúrgica Las Truchas". La Voz de Michoacán (1963). 


\section{REFERENCIAS}

Arriaga Rivera, Agustín. La política... como me la enseñaron. Recuerdos, añoranzas y realidades de mi vida. México: Editorial Consuelo Sánchez y Asociados, S. C., 2005.

Bremauntz, Alberto. Informe de labores, 1964-1965. Morelia: Universidad Michoacana de San Nicolás de Hidalgo, 1966.

Bremauntz, Alberto. México y la revolución socialista cubana. Morelia: Fimax Publicistas, 1966.

Bremauntz, Alberto. Setenta años de mi vida. Memorias y anécdotas. México: Ediciones Jurídico Sociales, 1968.

Gutiérrez, Ángel (recopilación, textos introductorios y presentación). Leyes Orgánicas de la Universidad Michoacana de San Nicolás de Hidalgo. Morelia: Universidad Michoacana de San Nicolás de Hidalgo, 2001.

Gutiérrez López, Miguel Ángel. En los límites de la autonomía. La reforma socialista en la Universidad Michoacana, 1934-1943. Zamora: El Colegio de Michoacán, 2011.

Macías Guillén, Pablo G. Luces y sombras.Testimonios nicolaitas. Morelia: Universidad Michoacana de San Nicolás de Hidalgo, 1981.

Mejía González, Adolfo. Michoacán ifeudo cardenista? Historia de una lucha estudiantil vencida con la traición y el asesinato. México: Editorial Nuevos Caminos, 1966.

Sánchez Díaz, Gerardo. “De Coalcomán al Colegio de San Nicolás. La infancia y los años juveniles de Natalio Vázquez Pallares". En La Nación dueña de su destino. Vida y obra de Natalio Vázquez Pallares, editado por Mario Nájera Espinoza, Gerardo Sánchez Díaz y Verónica Oikión Solano. Guadalajara: U de G/El Colegio de Michoacán/Universidad Michoacana de San Nicolás de Hidalgo, 2007.

López Mateos, Adolfo. VI Informe de Gobierno. http://www.diputados.gob.mx/cedia/sia/re/RE-ISS09-06-12.pdf (25/8/2017).

Luna Flores, Adrián. "Las escuelas particulares de comercio en Michoacán y su lucha por el reconocimiento oficial, 1920-1960". Río de Papel no 23 (2015): 57-79.

Rangel Hernández, Lucio. "La Universidad Michoacana, el movimiento estudiantil universitario michoacano y la solidaridad con la Revolución Cubana". Universidad Michoacana. Revista trimestral de ciencia, arte y cultura $\mathrm{n}^{\circ} 13$ (1994): 132-137.

Cómo citar:

Rangel Hernández, Lucio. El subsidio como arma represiva del Estado mexicano. La Universidad Michoacana de San Nicolás de Hidalgo durante la rectoría de Alberto Bremauntz (1963-1966)". Revista Historia de la Educación Latinoamericana. vol. 22 No. 34 (2020): 219-242

DOI: https://doi.org/10.19053/01227238.10896

(c) (i)@@ Esta obra está bajo una licencia Creative Commons. Reconocimiento-No Comercial-Sin Obra Derivada 2.5 Colombia. 